\title{
Docosahexaenoic acid is associated with endosteal circumference in long bones in young males with cystic fibrosis
}

\author{
Eva Gronowitz ${ }^{1}$, Mattias Lorentzon ${ }^{2}$, Claes Ohlsson ${ }^{2}$, Dan Mellström ${ }^{3}$ and Birgitta Strandvik ${ }^{1}$ \\ ${ }^{1}$ West Swedish CF Center, Sahlgrenska Academy, Gothenburg University, Queen Silvia Children's Hospital, 41685 Gothenburg, \\ Sweden \\ ${ }^{2}$ Center of Bone Research at Department of Medicine, Sahlgrenska Academy, Gothenburg University, Sahlgrenska University \\ Hospital, 41345 Gothenburg, Sweden \\ ${ }^{3}$ Department of Geriatrics, Sahlgrenska Academy, Gothenburg University, Sahlgrenska University Hospital, 41345 Gothenburg, \\ Sweden
}

(Received 3 January 2007 - Revised 25 April 2007 - Accepted 11 June 2007)

In children, but not adults with cystic fibrosis (CF), associations between essential fatty acids (FA) and bone mass have been reported. Low bone mineral density (BMD) is common in these patients. Previously we found a normal annual increase of BMD, suggesting a potential for attaining normal bone mass. The aim of the present study was to investigate phospholipid FA pattern in relation to bone in young adult men with CF compared with healthy controls. Fourteen male patients with CF were compared with forty-two healthy controls, using dual-energy X-ray absorptiometry for total bone, lumbar spine and femur and peripheral quantitative computerised tomography for tibia and radius. A questionnaire concerning physical activity and nutrition was used. FA in serum phospholipids were measured using capillary GLC. CF patients did not differ in physical activity and anthropometry from controls. There were no differences in bone parameters between the two groups, but patients chronically colonised with Pseudomonas aeruginosa had lower BMD than non-colonised patients. The trabecular BMD in the tibia differed between patients and controls, but not after adjustment for age and weight. The endosteal circumference of the radius was significantly associated with serum phospholipid concentration of DHA and inversely with the $n-6: n-3$ FA ratio in CF patients but not in controls. The present study showed that young physically active adult males with classical CF obtained similar bone mass as controls, although influenced by pseudomonas colonisation. The association between DHA and long bone endosteal circumference suggested a later peak bone mass in those with CF compared with controls.

Essential fatty acids: Radius: Tibia: Late puberty: Pseudomonas colonisation

Most patients with cystic fibrosis (CF) have a lipid abnormality involving both the $n-6$ and $n-3$ series of essential fatty acids $(E F A)^{1-3}$. We recently reported that the fatty acid composition of serum phospholipids was significantly associated with bone mineral density (BMD) in children, but not in adults, with $\mathrm{CF}^{4}$. We also previously reported a normal average annual accretion of bone mass ${ }^{5}$, which was in contrast to other studies reporting reduced bone accretion before peak bone mass and an accelerated bone loss in adults ${ }^{6-8}$. High prevalence, $40-75 \%$, of osteopenia and osteoporosis with fractures has been reported in adult patients with $\mathrm{CF}^{6-13}$. The low BMD has also been suggested to be linked to the cystic fibrosis transmembrane conductance regulator (CFTR) mutation, recently supported by reports of abnormal bone formation and resorption in CFTR $^{-1-}$ mice $^{14}$. The most common mutation in the CFTR gene, $\Delta F 508$, has been suggested as an independent risk factor for reduced $\mathrm{BMD}^{15}$.
Physical activity has been shown to have a stimulatory effect on bone mass accretion ${ }^{13,16-18}$. Infection and inflammation, which start early in life in $\mathrm{CF}$, have been reported to down modulate BMD by the effect of cytokines ${ }^{19,20}$, also revealed by increased routine inflammatory markers 5 . The influence of pancreatic insufficiency on fat absorption in $\mathrm{CF}$ patients might contribute to poor $\mathrm{Ca}$ absorption and low $\mathrm{BMD}^{21}$. The relatively low serum concentrations of vitamin D despite regular supplementation might further contribute to low bone mass ${ }^{5,21-23}$, although no correlation between the serum concentration of this vitamin and BMD has been reported in $\mathrm{CF}$ or healthy individuals $\mathrm{s}^{5,8,22,24,25}$. Many $\mathrm{CF}$ patients also have a delayed onset of puberty; also, low levels of serum testosterone and abnormal menstruation have been reported ${ }^{6,7,10-12,26}$. The use of corticosteroids mandatory after lung transplantation is another identified risk factor for low $\mathrm{BMD}^{7-10,12}$.

Abbreviations: BMC, bone mineral content; BMD, bone mineral density; CF, cystic fibrosis; CFTR, cystic fibrosis transmembrane conductance regulator; DXA, dual-energy X-ray absorptiometry; EFA, essential fatty acid; $\mathrm{FEV}_{1 \cdot 0}$, forced expiratory volume in $1 \mathrm{~s}$; LBM, lean body mass; LS, lumbar spine; pQCT, peripheral quantitative computerised tomography; vBMD, volumetric bone mineral density.

* Corresponding author: Dr Eva Gronowitz, fax +46 31 217023, email eva.gronowitz@vgregion.se 
EFA have been shown to be important for bone growth and density in animals ${ }^{27,28}$. A recent published paper from Sweden studying a cohort of young males showed that $n-3$ fatty acids, especially DHA, were positively associated with bone mineral accrual $^{29}$. Also in elderly patients and patients with renal disease, associations have been found between BMD, Ca metabolism and EFA ${ }^{30,31}$. In a Norwegian study, dietary saturated fat showed a positive relationship with BMD in healthy children $^{32}$. EFA deficiency is common in CF patients ${ }^{3}$, and is more prevalent at prepuberty ${ }^{33}$, a time usually considered to be a risk period for further decrease of BMD in $\mathrm{CF}$ patients ${ }^{23}$.

In contrast to most other $\mathrm{CF}$ centres worldwide, we regularly compensate for severe EFA deficiency in our patients ${ }^{34}$, which in light of our recent finding of an association ${ }^{5}$ between EFA status and BMD would potentially have an impact on bone growth. We have previously found that bone mass in the adult animal is dependent on the EFA intake of the pregnant and lactating rat by programming ${ }^{35,36}$, and in a recent publication neonatal bone mineral content (BMC) in human healthy term-born infants was shown to be related to the perinatal maternal and infant EFA status ${ }^{37}$. Since several studies have shown that newborns with $\mathrm{CF}$ have a high prevalence of EFA deficiency ${ }^{38,39}$ and further that EFA deficiency is associated with genotype ${ }^{3}$, the suggestion that the $\Delta$ F508 mutation is an independent risk factor for reduced BMD might be related to the fact that EFA deficiency seemed to be more common in patients with severe mutations ${ }^{3}$. Such a hypothesis would imply that it would be possible to influence BMC during growth and explain why we, contrary to others, obtained normal bone accrual in our patients ${ }^{5}$.

The aim of the present study was to investigate if our population of young adult men with $\mathrm{CF}$, who might have reached or were close to reaching their final height, had normal bone mass, compared with healthy Swedish men of similar age. Dual-energy X-ray absorptiometry (DXA) was used to measure total BMC and BMD and focused on the lumbar spine (LS) and hip, since those sites contain more trabecular bone. In addition, cortical bone mass was specifically measured by peripheral quantitative computerised tomography (pQCT). The results were related to serum phospholipid fatty acid pattern. Anthropometry, bacterial colonisation, pulmonary function, and dairy intake as the major source of $\mathrm{Ca}$, were also evaluated in relation to bone mass.

\section{Subjects and methods}

The study was conducted according to the Helsinki declaration and approved by the ethics committee at Gothenburg University (Sweden). Informed consent was obtained from patients and parents and from healthy participants.

\section{Subjects}

Fourteen men with $\mathrm{CF}$, age 21.6 (SD 2.2) years, were included. All sixteen male patients in the age group of 18-25 years who regularly attended our $\mathrm{CF}$ centre were asked to participate in the study, but two declined. Thirteen patients were diagnosed in infancy or early childhood and only one after the age of 10 years. Sweat tests were pathological $(>60 \mathrm{mmol} / \mathrm{l})$ in all patients. Eleven patients had two 'severe mutations'; ten were homozygous for the $\Delta \mathrm{F} 508$ mutation. Three were compound heterozygotes for the same mutation and one of those had the severe mutation, 394delTT. The other mutations found were R117C and R75Q and in one patient one mutation could not be identified; these three latter patients were pancreatic sufficient. The pancreatic-insufficient patients were all treated with pancreatic enzyme supplementation. Multivitamin supplementation, including $10 \mu \mathrm{g}$ vitamin $\mathrm{D}$ and extra vitamin $\mathrm{E}(\geq 0 \cdot 1 \mathrm{~g})$ were subscribed to all patients. All patients who, at the regular yearly check-up, disclosed low linoleic acid concentration in serum phospholipids were advised to add vegetable oil to their diets.

All patients had been physically active since diagnosis, as a part of our treatment policy ${ }^{40,41}$. The Swedish programme of physiotherapy for patients with $\mathrm{CF}$ includes individualised physiotherapy and physical activities, such as daily trampoline exercise and different sports, including regular endurance and strength training several times per week. This was modified by continuous education and home visits for adjustment and optimising the programme as the patients grew ${ }^{41}$. It also includes oral and inhalation therapy with mucolytics and bronchodilators to optimise airway clearance with devices according to the patients' preference in order to achieve optimal adherence to therapy. None of the patients were treated with steroids.

Forced vital capacity and forced expiratory volume in $1 \mathrm{~s}$ $\left(\mathrm{FEV}_{1.0}\right)$ were 103 (SD 22) and 94 (SD 24) \% of predicted values, respectively ${ }^{42,43}$. Only one of the patients (age 23 years) had an $\mathrm{FEV}_{1.0}$ less than $60 \%$, i.e. $31 \%$ of the predicted value. Seven patients were chronically colonised with Pseudomonas aeruginosa characterised by repeated growth of the bacteria in sputum for $\geq 6$ months and increased serum titres to pseudomonal exotoxin $\mathrm{A}^{44}$. One patient was intermittently colonised without increased serum antibody titres. Two patients were chronically colonised with Staphylococcus aureus. Two patients had CF-related diabetes mellitus and two were treated with ursodeoxycholic acid for mild biochemical liver disease ${ }^{45}$. All were in stable condition without signs of acute infection.

The two men with CF (age 20 and 23 years, respectively) who declined to participate in the study both had severe mutations, were pancreatic insufficient and chronically colonised with $P s$. aeruginosa. Their $\mathrm{FEV}_{1.0}$ was 85 and $65 \%$ of predicted values, respectively, and they had normal anthropometric data. Although a small sample, the studied CF group was thus representative for the male CF patients of the ages 18-25 years at our centre.

Forty-two healthy men from the same geographic area served as controls. The control subjects were a subgroup of the oldest individuals in a large study group, randomly identified using the national population register, contacted by telephone and asked to participate ${ }^{46}$. Their age was 19.5 (SD 0.2) years.

\section{Questionnaire}

A standardised questionnaire was used to collect information about weight-bearing physical activities (h/week) and dietary intake of dairy products, vegetables and vitamin supplementation $^{46}$. Puberty onset was reported by a self-assessment enquiry (early, average or late compared with schoolmates).

\section{Anthropometric measurements}

Height was measured using a wall-mounted stadiometer, and weight was measured to the nearest $0.1 \mathrm{~kg}$. The same trained 
staff carried out all the measurements. The $\mathrm{CV}$ were $<1 \%$ for these measurements. BMI $\left(\mathrm{kg} / \mathrm{m}^{2}\right)$ was calculated.

\section{Handgrip strength}

Handgrip strength was measured with the JAMAR ${ }^{\circledR}$ hydraulic hand dynamometer (Sammons Preston Rolyan, Bolingbrook, IL, USA); each hand was measured three times and the best result was used.

\section{Dual-energy X-ray absorptiometry}

Bone area, BMC and BMD of the whole body, total femur, femoral neck and LS (L I-L IV) were assessed using Lunar Prodigy equipment (GE Lunar Corp., Madison, WI, USA). Lean body mass (LBM), fat mass and fat percentage of body weight were also measured. The $\mathrm{CV}$ of the BMD measurements ranged from 0.5 to $0.9 \%$ and was based on measurements by repeated measurements on the same control. The measurement that was repeated included all steps of the measurement (everything from positioning the patient to image analysis) in order to cover every conceivable error of the measurement.

\section{Peripheral quantitative computerised tomography}

A pQCT device (XCT-2000; Stratec Medizintechnik GmbH, Pforzheim, Germany) was used to scan the non-dominant distal tibia and distal radius. The pQCT was calibrated every week, using a standard phantom, and once every $30 \mathrm{~d}$ using a cone phantom provided by the manufacturer. A $2 \mathrm{~mm}$ single tomographic slice was scanned with a voxel size of $0.50 \mathrm{~mm}$. The cortical volumetric BMD (vBMD; $\left.\mathrm{mg} / \mathrm{cm}^{3}\right)$, cortical BMC $(\mathrm{mg} / \mathrm{mm})$, cortical cross-sectional area $\left(\mathrm{mm}^{2}\right)$ and cortical thickness $(\mathrm{mm})$ were measured by scanning through the diaphysis at $25 \%$ of the bone length in the proximal direction at the distal end of the bones. Trabecular vBMD was measured by scanning through the metaphysis at $4 \%$ of the bone length in the proximal direction at the distal end of the bones. Tibia length was measured from the medial malleolus to the medial condyle, and forearm length was defined as the distance from the olecranon to the ulnar styloid process. The $\mathrm{CV}$ were less than $1 \%$ for all pQCT measurements, estimated by repeated measurements on the same control as described earlier in the DXA section.

\section{Fatty acids in serum phospholipids}

Blood samples were obtained in relation to the bone measurements and frozen at $-70^{\circ} \mathrm{C}$ until analysis within 2 weeks. After lipid extraction, phospholipids were fractionated on a single SEP-PAK aminopropyl cartridge (Waters Corp., Beverly, MA, USA), transmethylated and separated by capillary GLC in a Hewlett-Packard 6890 gas chromatograph (Palo Alto, CA, USA) as previously described ${ }^{4}$.

\section{Statistical analysis}

Mean values and standard deviations are given if not otherwise indicated. Statistical analyses were performed by StatView ${ }^{\circledR}$ 5.0 (SAS Institute Inc., Cary, NC, USA), using Spearman rank test and multiple regression analysis for correlation tests. Student's $t$ test was used for comparison between groups for normally distributed data, otherwise with non-parametric tests such as the Mann-Whitney $U$ test. Statistically significant difference was set at $P<0.05$.

\section{Results}

Table 1 summarises the clinical characteristics of $\mathrm{CF}$ patients and controls. The CF patients were slightly, but significantly, older than the control group. The anthropometric data were similar. There was no significant difference between reported duration of physical activity per week or handgrip strength between the two groups. The CF patients consumed more vitamin supplements $(P<0.0001)$ and more dairy products $(P<0.05)$ than the controls. The intake of vegetables was similar (data not shown). DXA did not reveal differences in bone parameters or LBM between CF patients and controls. Percentage of fat mass was lower in the patients (Table 2), but the difference disappeared when the one most severely ill patient $\left(\mathrm{FEV}_{1.0} 31 \%\right)$ was excluded, indicating that body composition was similar to controls in thirteen of the fourteen patients. Of the CF patients and the controls, 21 and $10 \%$ respectively considered themselves to have a late puberty; the difference was not significant, probably due to the low number of patients (Table 1). The BMD at all sites measured by DXA and the endosteal circumference measured by pQCT in relation to self-assessed puberty stage showed a similar trend in controls and $\mathrm{CF}$ patients. Fig. 1 illustrates this for $\mathrm{BMD}_{\mathrm{LS}}$ and the endosteal circumference of radius.

Cortical BMC, vBMD and periosteal and endosteal circumferences of tibia and radius did not differ between $\mathrm{CF}$ patients and controls. The trabecular vBMD in the tibia differed between patients and controls $(P=0.04$; Table 3$)$, but not after adjustment for age and weight (data not shown). There were no differences in bone parameters between patients with pancreatic insufficiency and those with pancreatic

Table 1. Clinical data in patients with cystic fibrosis (CF) and healthy controls

(Mean values and standard deviations)

\begin{tabular}{|c|c|c|c|c|}
\hline & \multicolumn{2}{|c|}{ CF patients ( $n$ 14) } & \multicolumn{2}{|c|}{ Controls ( $n$ 42) } \\
\hline & Mean & SD & Mean & SD \\
\hline Age (years) & $21 \cdot 6^{\star \star \star}$ & $2 \cdot 2$ & $19 \cdot 5$ & 0.2 \\
\hline Height $(\mathrm{cm})$ & $181 \cdot 1$ & 5.5 & $181 \cdot 7$ & $6 \cdot 5$ \\
\hline Sitting height $(\mathrm{cm})$ & $139 \cdot 0$ & $4 \cdot 3$ & $139 \cdot 4$ & 3.4 \\
\hline Weight $(\mathrm{kg})$ & $70 \cdot 6$ & 10.5 & $73 \cdot 6$ & $11 \cdot 1$ \\
\hline BMI $\left(\mathrm{kg} / \mathrm{m}^{2}\right)$ & 21.5 & 2.9 & $22 \cdot 3$ & $2 \cdot 7$ \\
\hline Heart rate (beats/min) & 73.5 & 16 & 73.7 & 13 \\
\hline Grip strength, left hand (kg) & $46 \cdot 4$ & $9 \cdot 0$ & $48 \cdot 4$ & $7 \cdot 0$ \\
\hline Grip strength, right hand $(\mathrm{kg})$ & $47 \cdot 6$ & $9 \cdot 1$ & $50 \cdot 0$ & $7 \cdot 2$ \\
\hline Physical activity (h/week) & $4 \cdot 3$ & $3 \cdot 0$ & $5 \cdot 2$ & $9 \cdot 6$ \\
\hline \multicolumn{5}{|l|}{ Puberty† } \\
\hline Early $(n)$ & 1 & & 4 & \\
\hline Average $(n)$ & 10 & & 33 & \\
\hline Late $(n)$ & 3 & & 4 & \\
\hline Dairy products (glasses/d) & $3 \cdot 8^{*}$ & 1.4 & $2 \cdot 7$ & $2 \cdot 0$ \\
\hline Cheese (slices/d) & $3 \cdot 3$ & $2 \cdot 2$ & $3 \cdot 2$ & 3.5 \\
\hline Vitamin supplementation $(n)$ & $12^{\star \star \star}$ & & 10 & \\
\hline
\end{tabular}

Value was significantly different from that of the control group: ${ }^{\star} P<0.05$, ${ }^{\star \star *} P<0.001$.

†One control missing. 
Table 2. Body composition and bone mass evaluated by dual-energy $\mathrm{X}$-ray absorptiometry in patients with cystic fibrosis (CF) and healthy controls

(Mean values and standard deviations)

\begin{tabular}{|c|c|c|c|c|}
\hline & \multicolumn{2}{|c|}{$\begin{array}{c}\text { CF patients } \\
(n 14)\end{array}$} & \multicolumn{2}{|c|}{ Controls (n 42) } \\
\hline & Mean & SD & Mean & SD \\
\hline Lean body mass $(\mathrm{kg})$ & $57 \cdot 7$ & 7.5 & $57 \cdot 1$ & $6 \cdot 4$ \\
\hline Fat mass $(\mathrm{kg})$ & $10 \cdot 2$ & $5 \cdot 1$ & $13 \cdot 5$ & $6 \cdot 4$ \\
\hline Fat (\% body weight) & $14 \cdot 1^{*}$ & 5.6 & $17 \cdot 7$ & $6 \cdot 0$ \\
\hline Bone mineral content, total $(\mathrm{g})$ & 3031 & 536 & 3219 & 455 \\
\hline \multicolumn{5}{|l|}{ Bone mineral density } \\
\hline Total $\left(\mathrm{g} / \mathrm{cm}^{2}\right)$ & $1 \cdot 22$ & $0 \cdot 1$ & $1 \cdot 25$ & 0.1 \\
\hline Lumbar spine $\left(\mathrm{g} / \mathrm{cm}^{2}\right)$ & $1 \cdot 19$ & 0.2 & $1 \cdot 22$ & 0.1 \\
\hline Total hip $\left(\mathrm{g} / \mathrm{cm}^{2}\right)$ & $1 \cdot 10$ & 0.2 & $1 \cdot 17$ & 0.2 \\
\hline Femoral neck $\left(\mathrm{g} / \mathrm{cm}^{2}\right)$ & $1 \cdot 16$ & 0.3 & $1 \cdot 18$ & 0.2 \\
\hline
\end{tabular}

${ }^{*}$ Mean value was significantly different from that of the control group $(P<0.05)$.

sufficiency or controls. Chronic colonisation with Ps. aeruginosa was associated with significantly lower total BMC and BMD measured by DXA, both compared with controls and with $\mathrm{CF}$ patients without pseudomonal colonisation $(P=0.01$ for each). $\mathrm{BMD}_{\mathrm{LS}}$ differed between controls and patients chronically colonised with $P$ s. aeruginosa $(P=0 \cdot 04)$. With pQCT, the chronically colonised patients showed lower cortical BMC and bone area in both tibia and radius than patients who were not colonised $(P=0.02$ for each). The colonised patients also differed from controls in cortical BMC, cortical thickness and cross-sectional area and trabecular BMD of the tibia $(P=0 \cdot 01$ for each). No differences were found in corresponding bone parameters of radius. Physical activity was similar in both chronically colonised and non-colonised patients (data not shown).

The serum concentration of fatty acids in phospholipids differed significantly in $\mathrm{CF}$ patients from those in controls (Table 4). The total SFA was decreased and MUFA increased. The oleic acid:stearic acid ratio was higher in CF patients than in controls, indicating an increased $\Delta 9$-desaturase activity $(P<0 \cdot 001)$. The molar concentration of eicosatrienoic acid

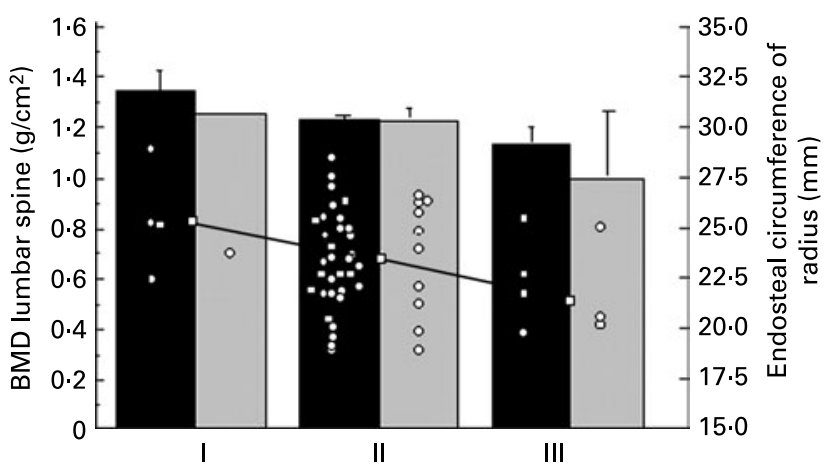

Fig. 1. Bone mineral density (BMD) of the lumbar spine measured by dualenergy X-ray absorptiometry in fourteen patients with cystic fibrosis $(\square)$ and forty-two healthy controls ( $\boldsymbol{\square})$ in relation to self-assessed onset of puberty (early (I), average (II) or late (III)), as reported in the questionnaire. Values are means, with their standard errors represented by vertical bars. Endosteal circumference of radius $(O)$ measured by peripheral quantitative computerised tomography. Median $(\square)$ of endosteal circumference for the different puberty stages showed a significant trend $(r-0.27 ; P<0.05)$
Table 3. Bone parameters measured by peripheral quantitative computerised tomography in patients with cystic fibrosis (CF) and healthy controls

(Mean values and standard deviations)

\begin{tabular}{|c|c|c|c|c|}
\hline & \multicolumn{2}{|c|}{$\begin{array}{c}\text { CF patients } \\
(n 14)\end{array}$} & \multicolumn{2}{|c|}{ Controls ( $n$ 42) } \\
\hline & Mean & SD & Mean & SD \\
\hline \multicolumn{5}{|l|}{ Tibia } \\
\hline Bone length (mm) & 393.9 & $14 \cdot 7$ & $406 \cdot 1$ & $21 \cdot 4$ \\
\hline Cortical BMC (mg/mm) & 295.8 & $44 \cdot 9$ & 313.7 & 39 \\
\hline Cortical vBMD $\left(\mathrm{mg} / \mathrm{mm}^{3}\right)$ & 1160 & 20 & 1164 & 21 \\
\hline Cortical CSA $\left(\mathrm{mm}^{2}\right)$ & $253 \cdot 8$ & 38 & $270 \cdot 5$ & 34 \\
\hline Cortical thickness (mm) & $4 \cdot 3$ & 0.7 & 4.5 & 0.5 \\
\hline Periosteal circumference $(\mathrm{mm})$ & $72 \cdot 6$ & $4 \cdot 3$ & 74.5 & $4 \cdot 7$ \\
\hline Endosteal circumference (mm) & 45.4 & $5 \cdot 7$ & $46 \cdot 3$ & 4.9 \\
\hline Trabecular vBMD $\left(\mathrm{mg} / \mathrm{mm}^{3}\right)$ & $245 \cdot 1^{*}$ & $43 \cdot 8$ & $270 \cdot 3$ & $37 \cdot 6$ \\
\hline \multicolumn{5}{|l|}{ Radius } \\
\hline Bone length (mm) & $284 \cdot 3$ & $11 \cdot 2$ & $283 \cdot 6$ & $12 \cdot 2$ \\
\hline Cortical BMC (mg/mm) & $113 \cdot 8$ & $19 \cdot 9$ & $114 \cdot 3$ & $15 \cdot 2$ \\
\hline Cortical vBMD $\left(\mathrm{mg} / \mathrm{mm}^{3}\right)$ & 1177 & 20 & 1174 & 22 \\
\hline Cortical CSA $\left(\mathrm{mm}^{2}\right)$ & 96.6 & $16 \cdot 2$ & 97.4 & $12 \cdot 6$ \\
\hline Cortical thickness (mm) & $3 \cdot 0$ & 0.5 & 3.0 & 0.3 \\
\hline Periosteal circumference $(\mathrm{mm})$ & $41 \cdot 8$ & $2 \cdot 8$ & $42 \cdot 1$ & $2 \cdot 8$ \\
\hline Endosteal circumference (mm) & $23 \cdot 1$ & $2 \cdot 7$ & 23.5 & 2.5 \\
\hline Trabecular vBMD $\left(\mathrm{mg} / \mathrm{mm}^{3}\right)$ & $220 \cdot 8$ & $54 \cdot 2$ & 228.9 & 41.5 \\
\hline
\end{tabular}

BMC, bone mineral content; vBMD, volumetric bone mineral density; CSA, crosssectional area.

${ }^{*}$ Mean value was significantly different from that of the control group $(P<0.05)$.

and the eicosatrienoic acid:arachidonic acid ratio were increased, suggesting EFA deficiency in the patients with CF. This was supported by the significantly lower concentration of linoleic acid in the patients. The dihomo- $\gamma$-linolenic acid:linoleic acid ratio indicated a higher $\Delta 6$-desaturase activity in the patients than controls $(P<0.001)$, but a lower $\Delta 5$-desaturase activity, as represented by the arachidonic acid: dihomo- $\gamma$-linolenic acid ratio $(P=0 \cdot 02$; Table 4$)$. No correlation was found between the desaturase activities and bone parameters (data not shown). In the patients with $\mathrm{CF}$, the endosteal circumference of the radius was inversely correlated to the $n-6: n-3$ fatty acid ratio $(r-0.73 ; P<0.01 ;$ Fig. 2 (A)), but with a positive trend to cortical thickness $(r 0 \cdot 38 ; P=0 \cdot 18$; Fig. 2 (B)). This was related to the $n-3$ fatty acids, since the endosteal circumference was strongly correlated both to total $n-3$ and to the long-chain product, DHA $(r$ 0.79; $P<0.001$ for both; Fig. 2 (C)). As expected then, the corresponding association with cortical thickness was negative $(r-0.57$; $P=0.035$; Fig. 2 (D)). The same trend of correlations was seen in the tibia although not significant (DHA, $r$ 0.38, $P=0 \cdot 18 ; n-6: n-3$ fatty acids, $r-0 \cdot 28, P=0 \cdot 31)$. A positive correlation was also found between arachidonic acid:DHA and cortical thickness, $(r 0.57 ; P<0.05)$, suggesting that the balance between $n-6: n-3$ fatty acids was of importance for skeletal size in the CF patients. This was further indicated by bone length being negatively associated with arachidonic acid both in the radius and tibia in the healthy controls, being $r-0.44(P<0.01)$ and $r-0.32(P<0.05)$, respectively.

Correlations between bone parameters and BMI, LBM, fat mass and $\mathrm{FEV}_{1.0}$ in patients with $\mathrm{CF}$ and controls are shown in Table 5. Multiple regression analyses showed that LBM was stronger correlated to BMC, analysed with both DXA and pQCT, than was BMI in both $\mathrm{CF}$ patients and controls 
Table 4. Molar percentage of major fatty acids in serum phospholipids in patients with cystic fibrosis (CF) and healthy controls

(Mean values and standard deviations)

\begin{tabular}{|c|c|c|c|c|}
\hline \multirow[b]{2}{*}{ Fatty acid } & \multicolumn{2}{|c|}{$\begin{array}{l}\text { CF patients } \\
\quad(n 14)\end{array}$} & \multicolumn{2}{|c|}{$\begin{array}{c}\text { Controls ( } n \\
42)\end{array}$} \\
\hline & Mean & SD & Mean & SD \\
\hline Myristic acid (14:0) & $0.55^{\star \star \star}$ & $0 \cdot 1$ & 0.43 & 0.1 \\
\hline Palmitic acid (16:0) & $31 \cdot 4$ & 1.7 & 31.9 & $1 \cdot 0$ \\
\hline Stearic acid $(18: 0)$ & $12 \cdot 1$ & $1 \cdot 1$ & $12 \cdot 6$ & 0.8 \\
\hline Palmitoleic acid (16:1n-7, n-9) & $0 \cdot 7^{\star \star \star}$ & 0.3 & 0.4 & 0.1 \\
\hline OA $(18: 1 n-7)$ & $11 \cdot 0^{\star \star *}$ & $1 \cdot 7$ & $9 \cdot 6$ & $1 \cdot 0$ \\
\hline ETA $(20: 3 n-9)$ & $0.5^{\star * *}$ & 0.5 & 0.15 & 0.05 \\
\hline$\Sigma$ SFA & $46 \cdot 5^{\star \star}$ & $1 \cdot 0$ & $47 \cdot 5$ & $1 \cdot 0$ \\
\hline$\Sigma$ MUFA & $14 \cdot 6^{\star \star \star}$ & 1.9 & $12 \cdot 6$ & $1 \cdot 0$ \\
\hline DGLA $(20: 3 n-6)$ & $3 \cdot 7^{\star \star \star}$ & 0.7 & 2.9 & 0.7 \\
\hline LA $(18: 2 n-6)$ & $20 \cdot 6^{\star \star}$ & $3 \cdot 2$ & $23 \cdot 0$ & $2 \cdot 1$ \\
\hline $\mathrm{AA}(20: 4 n-6)$ & $8 \cdot 2$ & $1 \cdot 0$ & $7 \cdot 9$ & $1 \cdot 1$ \\
\hline$\sum n-6$ & $33 \cdot 0$ & 2.9 & $34 \cdot 1$ & $1 \cdot 8$ \\
\hline$\alpha$-Linolenic acid (18:3n-3) & 0.6 & 0.1 & 0.5 & 0.3 \\
\hline EPA $(20: 5 n-3)$ & $1 \cdot 7^{\star}$ & 0.5 & 1.4 & 0.5 \\
\hline $\mathrm{DHA}(22: 6 n-3)$ & 3.4 & 0.8 & 3.8 & $1 \cdot 0$ \\
\hline$\sum n-3$ & $5 \cdot 5$ & $1 \cdot 0$ & $5 \cdot 5$ & $1 \cdot 3$ \\
\hline$\Sigma$ PUFA & $38 \cdot 9$ & $2 \cdot 6$ & $39 \cdot 8$ & 1.6 \\
\hline AA:DHA & $2 \cdot 6$ & 0.8 & $2 \cdot 2$ & 0.5 \\
\hline OA:LA & $0 \cdot 6^{\star \star \star}$ & 0.2 & 0.4 & $0 \cdot 1$ \\
\hline ETA:AA & $0.06^{\star * *}$ & 0.05 & 0.02 & 0.01 \\
\hline$\sum n-6: \Sigma n-3$ & $6 \cdot 2$ & $1 \cdot 3$ & 6.5 & 1.5 \\
\hline OA:18:0 ( $\Delta$ 9-desaturase) & $0.91^{\star * *}$ & 0.16 & 0.76 & 1.0 \\
\hline DGLA:LA ( $\Delta$ 6-desaturase) & $0 \cdot 18^{\star \star *}$ & 0.05 & 0.13 & 0.04 \\
\hline AA:DGLA ( $\Delta$ 5-desaturase) & $2 \cdot 32^{\star}$ & 0.69 & $2 \cdot 85$ & 0.75 \\
\hline
\end{tabular}

OA, oleic acid; ETA, eicosatrienoic acid; DGLA, dihomo- $\gamma$-linolenic acid; LA, linoleic acid; AA, arachidonic acid.

Mean value was significantly different from that of the control group: ${ }^{*} P \leq 0.05$, ${ }^{\star \star} P \leq 0.01,{ }^{\star \star \star} P \leq 0.001$

(data not shown). Mainly similar correlations were found in CF subjects and controls, supporting similar associations between body composition and bone mass. In patients with $\mathrm{CF}$, multiple regression analyses showed $\mathrm{FEV}_{1.0}$ to be the strongest predictor for cortical $\mathrm{BMC}$, eliminating the influence of BMI and $\mathrm{LBM}(P=0 \cdot 02)$.

\section{Discussion}

In this small group, but for our centre representative and nonselected male young adult patients with $\mathrm{CF}$, we found that cortical and trabecular BMC were not different from the healthy controls. The only difference found was in trabecular vBMD of the tibia. It might be speculated that this difference between $\mathrm{CF}$ patients and controls would be stronger if the group of $\mathrm{CF}$ patients had been larger. Many studies have shown that trabecular bone density is more affected in $\mathrm{CF}$ and associated with inflammatory markers ${ }^{5-11,13,19,20,22}$. Since the tibia and radius are the last bones to attain peak bone mass ${ }^{46}$, the finding might be complementary to the results that endosteal contraction in the radius was not finished in the CF patients. Further studies are indicated to determine if measurement of the tibia might be a more sensitive marker of low BMD than LS and femoral neck.

The present results are in line with our previous finding in a prospective 2-year study, where the average annual increase of $\mathrm{BMD}_{\mathrm{LS}}$ and $\mathrm{BMD}_{\text {femoral neck }}$ were normal in children and the levels constant in the adults ${ }^{5}$. These results differ markedly from most other reports ${ }^{6-13}$ and might be associated with many factors related to treatment. Our patient population does not differ genetically from most other studies ${ }^{47}$, but generally has a better growth, pulmonary function and $\mathrm{BMD}^{3-5,22}$

The present results first of all show that normal bone parameters are possible to obtain in a non-selected group of young men with classical $\mathrm{CF}$ and in whom $79 \%$ carried severe CFTR mutations. A few studies have shown that normal bone mass can be achieved in patients with CF compared with other patients of similar height, i.e. normal but stunted patients, both children and adults ${ }^{48,49}$. Our patients were compared with controls representative to the general population of similar age. It is interesting to note that despite the good condition of the patients, the influence of bacterial colonisation and lung function on bone mass was significant, implicating that the pulmonary treatment might be the strongest predictor of bone mass in $\mathrm{CF}$ in physically active patients ${ }^{5,23}$. It also implies that in a larger $\mathrm{CF}$ population there might have been a small, but significant, difference from controls.

In a recent study of adult patients with much more severe pulmonary impairment and a high percentage of steroid treatment, an association was found with the $\Delta$ F508 mutation independent of lung function and malnutrition ${ }^{19}$. Others and we have not found such a relationship and it cannot be excluded that the relationship with $\Delta$ F508 might reflect a common delineator such as EFA deficiency, which has been shown to be related to genotype ${ }^{3}$. In our centre the EFA deficiency in the patients is balanced by oral supplementation of vegetable oils or in severe cases by lipid emulsions intravenously ${ }^{34}$. The extent of EFA deficiency is therefore probably lower than in many other centres.

Late puberty and low testosterone concentrations have been shown to be common in CF patients, and might probably contribute to a later achievement of peak bone mass $6,7,9-11,26$. It has been shown that free testosterone is a positive predictor of cortical bone size in young men ${ }^{50}$. Although we had no possibility to measure testosterone in the present study, the self-assessment suggested that more CF patients than controls considered themselves to have a late puberty (Table 1). This might indicate that a significant difference of BMD might be found in a larger population of patients, as indicated by the significantly lower trabecular vBMD of tibia in the CF patients, which disappeared when adjusted for weight and height. Late puberty will also include a later peak bone mass, which might explain why an association between fatty acids and bone mass was only found in the CF patients but not in the controls, corroborating our previous results in $\mathrm{CF}^{4}$. During growth the endosteal circumference increases in the long bones, but after cessation of linear growth the endosteal circumference restrains, when the cortex grows thicker ${ }^{46}$. The long bones are the last ones, where this can be measured. Self-assessment of puberty and peak height velocity, which occurs at the time of puberty, have been found strongly correlated $^{51}$, the correlation coefficient being $r 0.50(P<0 \cdot 01)$ in the controls.

The trend between endosteal circumference and selfassessed puberty supports an earlier report of a large healthy population $^{46}$ (Fig. 1). Since it has previously been shown a relationship between fatty acids and bone mass in children 

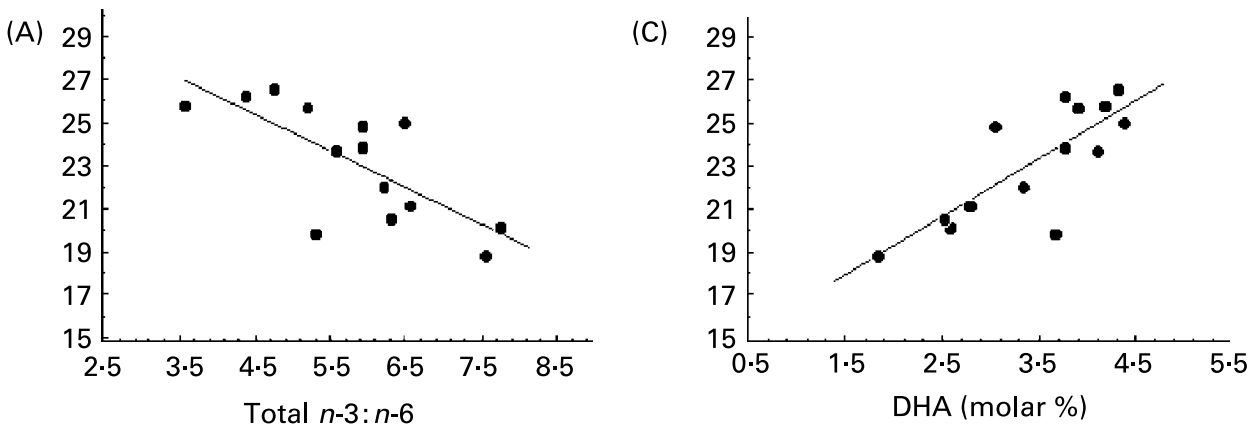

(B)

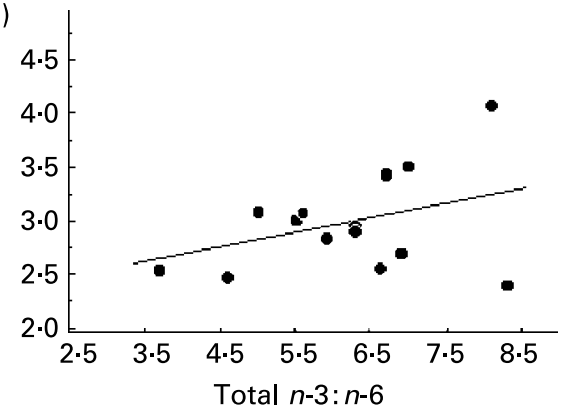

(D)

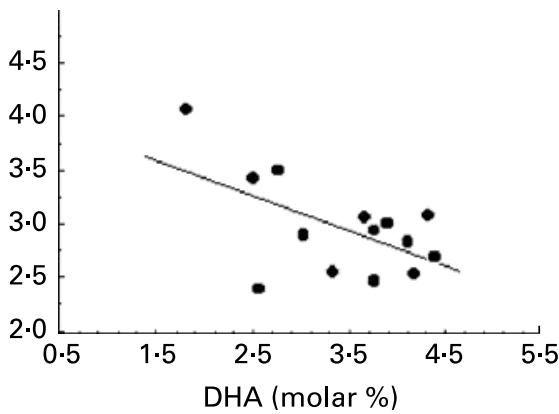

Fig. 2. (A) Total $n-6: n-3$ fatty acids ratio in relation to the endosteal circumference of radius in fourteen patients with cystic fibrosis $(r-0.73 ; P=0.03)$; (B) $n-6: n-3$ fatty acids ratio in relation to the cortical thickness of radius $(r 0.38 ; P=0.18) ;(C)$ molar concentration of DHA in serum phospholipids in relation to the endosteal circumference of radius $(r 0.79 ; P=0.0008)$; (D) molar concentration of DHA in serum phospholipids in relation to the cortical thickness of radius $(r-0.57 ; P=0.035)$.

but not in adults with $\mathrm{CF}^{4}$ and a relationship between $n-3$ fatty acids in healthy men ${ }^{29}$, the association in the present study between EFA and endosteal circumference and thickness only in the $\mathrm{CF}$ patients suggests that the patients were later in puberty than the controls. It also implies that EFA, especially the $n-6: n-3$ ratio, are of importance for the final bone modelling of the long bones (Fig. 2). High concentrations of DHA were associated with thinner cortical

Table 5. Correlations between clinical parameters and bone parameters in fourteen patients with cystic fibrosis (CF) and forty-two healthy controls, measured by dual energy X-ray absorptiometry (DXA) and peripheral quantitative computerised tomography (pQCT)

\begin{tabular}{|c|c|c|c|c|c|c|c|}
\hline & \multicolumn{2}{|c|}{ BMI $\left(\mathrm{kg} / \mathrm{m}^{2}\right)$} & \multicolumn{2}{|c|}{ LBM (kg) } & \multicolumn{2}{|c|}{ Total fat mass $(\mathrm{kg})$} & \multirow{2}{*}{$\begin{array}{c}\mathrm{FEV}_{1.0}(\% \text { of predicted }) \\
\text { CF }\end{array}$} \\
\hline & $\mathrm{CF}$ & Controls & CF & Controls & $\mathrm{CF}$ & Controls & \\
\hline \multicolumn{8}{|l|}{ DXA } \\
\hline Total BMC & $0.67^{\star *}$ & $0.50^{\star \star \star}$ & $0 \cdot 83^{\star \star \star}$ & $0.79^{\star \star \star}$ & 0.48 & $0.31^{*}$ & $0.83^{\star \star \star}$ \\
\hline Total BMD & $0.65^{\star \star}$ & $0.47^{\star \star}$ & $0.69^{\star *}$ & $0.59^{\star \star *}$ & 0.50 & 0.22 & $0.82^{\star \star \star}$ \\
\hline BMD of lumbar spine & $0.79^{\star \star \star}$ & 0.28 & $0.77^{\star \star \star}$ & $0.47^{\star \star}$ & $0.56^{*}$ & 0.10 & $0.78^{\star \star \star}$ \\
\hline BMD of total femur & 0.20 & 0.29 & $0.53^{\star}$ & $0.44^{\star}$ & 0.01 & -0.01 & $0.58^{*}$ \\
\hline BMD of femoral neck & 0.42 & 0.30 & $0.57^{*}$ & $0.41^{* *}$ & -0.06 & 0.02 & 0.42 \\
\hline pQCT & & & & & & & \\
\hline \multicolumn{8}{|l|}{ Tibia } \\
\hline Cortical BMC & $0.58^{*}$ & $0.43^{\star *}$ & $0.68^{\star \star}$ & $0.68^{\star * *}$ & 0.47 & 0.09 & $0.85^{\star * *}$ \\
\hline Cortical BMD & 0.07 & -0.12 & 0.05 & -0.03 & 0.01 & 0.02 & 0.20 \\
\hline Cortical area & $0.59^{\star}$ & $0.44^{\star \star}$ & $0 \cdot 70^{* *}$ & $0.68^{\star * *}$ & 0.48 & 0.09 & $0.85^{\star \star \star}$ \\
\hline Cortical thickness & 0.49 & 0.29 & $0.54^{\star}$ & $0.32^{*}$ & 0.44 & 0.05 & $0.73^{*}$ \\
\hline Trabecular BMD & 0.52 & 0.20 & 0.49 & 0.22 & 0.43 & -0.01 & $0.67^{* *}$ \\
\hline Trabecular area & 0.36 & 0.27 & $0.74^{\star \star}$ & $0.58^{\star \star \star}$ & $0 \cdot 10$ & 0.14 & $0.54^{*}$ \\
\hline Periosteal circumference & 0.37 & $0.40^{\star \star}$ & 0.49 & $0.73^{\star \star \star}$ & 0.25 & 0.06 & 0.50 \\
\hline Endosteal circumference & -0.08 & 0.20 & -0.03 & $0.50^{\star \star *}$ & -0.13 & 0.03 & -0.20 \\
\hline \multicolumn{8}{|l|}{ Radius } \\
\hline Cortical BMC & 0.44 & 0.21 & $0.59^{\star}$ & $0.46^{\star *}$ & 0.34 & -0.06 & $0.65^{\star \star}$ \\
\hline Cortical BMD & 0.41 & 0.01 & 0.32 & 0.03 & 0.48 & 0.10 & $0.58^{*}$ \\
\hline Cortical area & 0.43 & 0.22 & $0.59^{\star}$ & $0.47^{\star \star}$ & 0.31 & -0.07 & $0.63^{\star}$ \\
\hline Cortical thickness & 0.23 & 0.21 & 0.39 & $0 \cdot 30^{\star}$ & 0.18 & -0.06 & $0.54^{*}$ \\
\hline Trabecular BMD & 0.20 & -0.05 & 0.37 & 0.001 & 0.09 & -0.20 & $0.54^{*}$ \\
\hline Trabecular area & 0.43 & 0.29 & 0.52 & $0.52^{* \star *}$ & 0.25 & 0.18 & 0.29 \\
\hline Periosteal circumference & $0.60^{*}$ & 0.18 & $0.72^{\star *}$ & $0.49^{\star \star \star}$ & 0.42 & -0.06 & $0.62^{*}$ \\
\hline Endosteal circumference & 0.37 & 0.07 & 0.32 & $0.35^{\star}$ & 0.25 & -0.03 & 0.06 \\
\hline
\end{tabular}

LBM, lean body mass; $\mathrm{FEV}_{1.0}$, forced expiratory volume in $1 \mathrm{~s}$; BMC, bone mineral content; BMD, bone mineral density. Regression coefficient was significant: ${ }^{\star} P<0.05,{ }^{\star \star} P<0.01,{ }^{\star \star \star} P<0.001$. 
thickness and a similar association was found between maternal blood erythrocyte DHA concentration and bone mineralisation of both femur and LS in healthy newborns ${ }^{37}$. That a balance between the $n-6$ and $n-3$ fatty acids is important was also found in the animal studies, where a high- $n-3$ diet perinatally resulted in lower bone mass in the adult animal ${ }^{35}$. This implies that a selective supplementation of DHA to CF patients as well as to other categories of patients might have other non-desirable effects.

\section{Conclusion}

Contrary to all previous reports of adult CF patients with high prevalence of osteoporosis ${ }^{6-13}$, the present study showed that normal BMD can be obtained in a small but non-selected group of young $\mathrm{CF}$ men with classical severe $\mathrm{CF}$. Several factors in our treatment policy might be responsible:

social insurance did not limit the use of expensive antibiotics in the treatment of mild exacerbations of pulmonary disease ${ }^{52}$;

physical activity has been a part of the regular treatment regimen from an early age on ${ }^{40,41}$;

there is a restricted use of steroids;

fat is supplemented on a more-or-less regular basis, contributing to normal anthropometric data, although a total normalisation of the phospholipid fatty acid pattern was not obtained ${ }^{34}$.

We suggest that one common denominator for the previously reported association of low BMD and the $\Delta \mathrm{F} 508$ mutation might be the lipid abnormality ${ }^{1,2,27}$. Such association can be explored by early nutritional support including EFA as suggested by the Wisconsin CF Neonatal Screening Group ${ }^{53}$, as well as by other prospective intervention investigations.

\section{Acknowledgements}

The authors are grateful to Sofia Heigis, Sarah McGovern, Emelie Svensson, Martin Svensson and Veronika Sjöstrand for performing the DXA and pQCT scans. The present study was supported by grants from the Faculty of Medicine, Gothenburg University and the Swedish Association of Cystic Fibrosis.

\section{References}

1. Carlstedt-Duke J, Bronnegard M \& Strandvik B (1986) Pathological regulation of arachidonic acid release in cystic fibrosis: the putative basic defect. Proc Natl Acad Sci USA 83, 9202-9206.

2. Miele L, Cordella-Miele E, Xing M, Frizzell R \& Mukherjee $\mathrm{AB}(1997)$ Cystic fibrosis gene mutation $(\Delta \mathrm{F} 508)$ is associated with an intrinsic abnormality in $\mathrm{Ca}^{2+}$-induced arachidonic acid release by epithelial cells. DNA Cell Biol 16, 749-759.

3. Strandvik B, Gronowitz E, Enlund F, Martinsson $T$ \& Wahlstrom J (2001) Essential fatty acid deficiency in relation to genotype in patients with cystic fibrosis. J Pediatr 139, $650-655$

4. Gronowitz E, Mellstrom D \& Strandvik B (2006) Serum phospholipid fatty acid pattern is associated with bone mineral density in children, but not adults, with cystic fibrosis. $\mathrm{Br} \mathrm{J}$ Nutr 95, 1159-1165.
5. Gronowitz E, Mellstrom D \& Strandvik B (2004) Normal annual increase of bone mineral density during two years in patients with cystic fibrosis. Pediatrics 114, 435-442.

6. Haworth CS, Selby PL, Horrocks AW, Mawer EB, Adams JE \& Webb AK (2002) A prospective study of change in bone mineral density over one year in adults with cystic fibrosis. Thorax 57, 719-723.

7. Bhudhikanok GS, Wang MC, Marcus R, Harkins A, Moss RB \& Bachrach LK (1998) Bone acquisition and loss in children and adults with cystic fibrosis: a longitudinal study. J Pediatr 133, $18-27$.

8. Bianchi ML, Romano G, Saraifoger S, Costantini D, Limonta C \& Colombo C (2006) BMD and body composition in children and young patients affected by cystic fibrosis. $J$ Bone Miner Res 21, 388-396.

9. Conway SP, Morton AM, Oldroyd B, Truscott JG, White H, Smith AH \& Haigh I (2000) Osteoporosis and osteopenia in adults and adolescents with cystic fibrosis: prevalence and associated factors. Thorax $\mathbf{5 5}, \mathbf{7 9 8}-804$.

10. Bhudhikanok GS, Lim J, Marcus R, Harkins A, Moss RB \& Bachrach LK (1996) Correlates of osteopenia in patients with cystic fibrosis. Pediatrics 97, 103-111.

11. Baroncelli GI, De Luca F, Magazzu G, Arrigo T, Sferlazzas C, Catena C, Bertelloni S \& Saggese G (1997) Bone demineralization in cystic fibrosis: evidence of imbalance between bone formation and degradation. Pediatr Res 41, 397-403.

12. Aris RM, Renner JB, Winders AD, Buell HE, Riggs DB, Lester GE \& Ontjes DA (1998) Increased rate of fractures and severe kyphosis: sequelae of living into adulthood with cystic fibrosis. Ann Intern Med 128, 186-193.

13. Buntain HM, Greer RM, Schluter PJ, Wong JC, Batch JA, Potter JM, Lewingdon PJ, Powell E, Wainwright CE \& Bell SC (2004) Bone mineral density in Australian children, adolescents and adults with cystic fibrosis: a controlled cross sectional study. Thorax 59, 149-155.

14. Dif F, Marty C, Baudoin C, de Vernejoul MC \& Levi G (2004) Severe osteopenia in CFTR-null mice. Bone 35, $595-603$.

15. King SJ, Topliss DJ, Kotsimbos T, Nyulasi IB, Bailey M, Ebeling PR \& Wilson JW (2005) Reduced bone density in cystic fibrosis: F508 mutation is an independent risk factor. Eur Respir J 25, 54-61.

16. Frangolias DD, Pare PD, Kendler DL, Davidson AG, Wong L, Raboud J \& Wilcox PG (2003) Role of exercise and nutrition status on bone mineral density in cystic fibrosis. J Cyst Fibros 2, $163-170$.

17. Sundberg M, Gardsell P, Johnell O, Karlsson MK, Ornstein E, Sandstedt B \& Sernbo I (2002) Physical activity increases bone size in prepubertal boys and bone mass in prepubertal girls: a combined cross-sectional and 3-year longitudinal study. Calcif Tissue Int 71, 406-415.

18. Lorentzon M, Mellstrom D \& Ohlsson C (2005) Association of amount of physical activity with cortical bone size and trabecular volumetric BMD in young adult men: the GOOD study. J Bone Miner Res 20, 1936-1943.

19. Haworth CS, Selby PL, Webb AK, Martin L, Elborn JS, Sharples LD \& Adams JE (2004) Inflammatory related changes in bone mineral content in adults with cystic fibrosis. Thorax $\mathbf{5 9}$, 613-617.

20. Conway SP (2001) Impact of lung inflammation on bone metabolism in adolescents with cystic fibrosis. Paediatr Respir Rev 2, 324-331.

21. Lark RK, Lester GE, Ontjes DA, Blackwood AD, Hollis BW, Hensler MM \& Aris RM (2001) Diminished and erratic absorption of ergocalciferol in adult cystic fibrosis patients. Am J Clin Nutr 73, 602-606. 
22. Gronowitz E, Garemo M, Lindblad A, Mellstrom D \& Strandvik B (2003) Decreased bone mineral density in normal-growing patients with cystic fibrosis. Acta Paediatr 92, 688-693.

23. Aris RM, Merkel PA, Bachrach LK, et al. (2005) Guide to bone health and disease in cystic fibrosis. J Clin Endocrinol Metab 90, 1888-1896.

24. Guler T, Sivas F, Baskan BM, Gunesen O, Alemdaroglu E \& Ozoran K (2007) The effect of outfitting style on bone mineral density. Rheumatol Int 27, 723-727.

25. Hogstrom M, Nordstrom A \& Nordstrom P (2006) Relationship between vitamin $\mathrm{D}$ metabolites and bone mineral density in young males: a cross-sectional and longitudinal study. Calcif Tissue Int 79, 95-101.

26. Leifke E, Friemert M, Heilmann M, Puvogel N, Smaczny C, von zur Muhlen A \& Brabant G (2003) Sex steroids and body composition in men with cystic fibrosis. Eur $J$ Endocrinol 148, 551-557.

27. Watkins BA, Lippman HE, Le Bouteiller L, Li Y \& Seifert MF (2001) Bioactive fatty acids: role in bone biology and bone cell function. Prog Lipid Res 40, 125-148.

28. Holman R (1968) Essential fatty acid deficiency. Prog Chem Fats Other Lipids 9, 279-348.

29. Hogstrom M, Nordstrom P \& Nordstrom A (2007) n-3 Fatty acids are positively associated with peak bone mineral density and bone accrual in healthy men: the NO2 Study. Am J Clin Nutr 85, 803-807.

30. Baggio B, Budakovic A, Ferraro A, Checchetto S, Priante G, Musacchio E, Manzato E, Zaninotto M \& Maresca MC (2005) Relationship between plasma phospholipid polyunsaturated fatty acid composition and bone disease in renal transplantation. Transplantation 80, 1349-1352.

31. Kruger MC, Coetzer H, de Winter R, Gericke G \& van Papendorp DH (1998) Calcium, $\gamma$-linolenic acid and eicosapentaenoic acid supplementation in senile osteoporosis. Aging (Milano) 10, 385-394.

32. Gunnes M \& Lehmann EH (1995) Dietary calcium, saturated fat, fiber and vitamin $\mathrm{C}$ as predictors of forearm cortical and trabecular bone mineral density in healthy children and adolescents. Acta Paediatr 84, 388-392.

33. Lai HC, Kosorok MR, Laxova A, Davis LA, FitzSimmon SC \& Farrell PM (2000) Nutritional status of patients with cystic fibrosis with meconium ileus: a comparison with patients without meconium ileus and diagnosed early through neonatal screening. Pediatrics 105, 53-61.

34. Strandvik B (1995) Nutrition in mucoviscidos. In Infant Nutrition in Special Situations, pp. 305-312 [R Ghraf, P Aggett, J Lifschitz, J Walker-Smith and J Morán, editors]. Madrid: Ergon.

35. Korotkova M, Ohlsson C, Hanson LA \& Strandvik B (2004) Dietary $n-6: n-3$ fatty acid ratio in the perinatal period affects bone parameters in adult female rats. Br J Nutr 92, 643-648.

36. Korotkova M, Ohlsson C, Gabrielsson B, Hanson LA \& Strandvik B (2005) Perinatal essential fatty acid deficiency influences body weight and bone parameters in adult male rats. Biochim Biophys Acta 1686, 248-254.

37. Weiler H, Fitzpatrick-Wong S, Schellenberg J, McCloy U, Veitch R, Kovacs H, Kohut J \& Kin Yuen C (2005) Maternal and cord blood long-chain polyunsaturated fatty acids are predictive of bone mass at birth in healthy term-born infants. Pediatr Res 58, 1254-1258.
38. Lloyd-Still JD, Johnson SB \& Holman RT (1991) Essential fatty acid status and fluidity of plasma phospholipids in cystic fibrosis infants. Am J Clin Nutr 54, 1029-1035.

39. van Egmond AW, Kosorok MR, Koscik R, Laxova A \& Farrell PM (1996) Effect of linoleic acid intake on growth of infants with cystic fibrosis. Am J Clin Nutr 63, 746-752.

40. Blomquist M, Freyschuss U, Wiman LG \& Strandvik B (1986) Physical activity and self treatment in cystic fibrosis. Arch Dis Child 61, 362-367.

41. Lannefors L, Button BM \& McIlwaine M (2004) Physiotherapy in infants and young children with cystic fibrosis: current practice and future developments. J R Soc Med 97, Suppl. 44, $8-25$.

42. Quanjer PH, Tammeling GJ, Cotes JE, Pedersen OF, Peslin R \& Yernault JC (1993) Lung volumes and forced ventilatory flows. Report Working Party Standardization of Lung Function Tests, European Community for Steel and Coal. Official statement of the European Respiratory Society. Eur Respir J 16, 5-40.

43. Solymar L, Aronsson PH, Bake B \& Bjure J (1980) Nitrogen single breath test, flow-volume curves and spirometry in healthy children, 7-18 years of age. Eur J Respir Dis 61, 275-286.

44. Hollsing AE, Granstrom M, Vasil ML, Wretlind B \& Strandvik B (1987) Prospective study of serum antibodies to Pseudomonas aeruginosa exoproteins in cystic fibrosis. J Clin Microbiol 25, $1868-1874$.

45. Lindblad A, Glaumann H \& Strandvik B (1999) Natural history of liver disease in cystic fibrosis. Hepatology 30, 1151-1158.

46. Lorentzon M, Mellstrom D \& Ohlsson C (2005) Age of attainment of peak bone mass is site specific in Swedish men - The GOOD study. J Bone Miner Res 20, 1223-1227.

47. Strandvik B, Björck E, Fallström M, Gronowitz E, Thountzouris J, Lindblad A, Markiewicz D, Wahlström J, Tsui LC \& Zielenski J (2001) Spectrum of mutations in the CFTR gene of patients with classical and atypical forms of cystic fibrosis from southwestern Sweden: identification of 12 novel mutations. Genet Test 5, 235-242.

48. Salamoni F, Roulet M, Gudinchet F, Pilet M, Thiebaud D \& Burckhardt P (1996) Bone mineral content in cystic fibrosis patients: correlation with fat-free mass. Arch Dis Child 74, 314-318.

49. Hardin DS, Arumugam R, Seilheimer DK, LeBlanc A \& Ellis KJ (2001) Normal bone mineral density in cystic fibrosis. Arch Dis Child 84, 363-368.

50. Lorentzon M, Swanson C, Andersson N, Mellstrom D \& Ohlsson C (2005) Free testosterone is a positive, whereas free estradiol is a negative, predictor of cortical bone size in young Swedish men: the GOOD study. J Bone Miner Res 20, 1334-1341.

51. Kindblom JM, Lorentzon M, Norjavaara E, Hellqvist A, Nilsson S, Mellström D \& Ohlsson C (2006) Pubertal timing predicts previous fractures and BMD in young adult men: the GOOD study. J Bone Miner Res 21, 790-795.

52. Strandvik B (1988) Antibiotic therapy of pulmonary infections in cystic fibrosis. Dosage schedules and duration of treatment. Chest 94, Suppl. 2, 146S-149S.

53. Shoff SM, Ahn HY, Davis L \& Lai H (2006) Temporal associations among energy intake, plasma linoleic acid, and growth improvement in response to treatment initiation after diagnosis of cystic fibrosis. Pediatrics 117, 391-400. 